\title{
LA PERSONNE MORALE SELON LE DROIT INTERNATIONAL PRIVÉ BRÉSILIEN ACTUEL
}

\section{LEGAL PERSONS UNDER CURRENT BRAZILIAN PRIVATE INTERNATIONAL LAW}

Carmen Tiburcio

\begin{abstract}
Maître et Docteur en Droit International par la Faculté de Droit de l'Université de Virginia, aux États-Unis. Professeur Titulaire de Droit International Privé de l'Université de l'État de Rio de Janeiro - UERJ, Brésil.

Cet article s'origine d'une conférence présentée à L'Université de Toulouse, France, à 2010, pour laquelle l'auteur tient à remercier Lucas Hermeto pour sa collaboration dans les recherches. Gabriel Almeida, Isabella Jordani et Stela Porto ont aussi contribué dans les recherches de droit brésilien.

cbtiburc@uninet.com.br
\end{abstract}

Reçu: 2016-04-29. Accepté: 2016-07-04.

Resumé: Pour déterminer la nationalité des personnes morales, il faut déterminer certains critères. Le Droit International Privé reconnu trois, qui sont: i) de l'incorporation; ii) du siège social; et iii) du contrôle. Au Brésil, il est adopté le critère de l'incorporation. En conséquence, une société brésilienne est celle qui a été incorporé au Brésil et qui a son siège administratif dans ce pays. La juridiction brésilienne sera alors compétente pour juger de ce qui se réfère à des entreprises brésiliennes, mais pas seulement pour eux. Les tribunaux brésiliens peuvent également juger les personnes morales étrangères qui y ont une agence, une filiale ou une succursale au Brésil.

Mots-Clés: Nationalité - Personnes morales - Etreprises étrangères

Abstract: Private International Law traditionally acknowledges three criteria to determine the nationality of legal entities, which are the place of: i) the incorporation; or ii) the registered office; or iii) its control . Specifically in relation to the Brazilian Law, a company is deemed as Brazilian, should it had been incorporated in Brazil and should it have its headquarters in that country. Brazilian courts will, thus, be competent to exert authority and rule matters related to Brazilian companies. 
However, Brazilian courts may also settle controversies regarding legal entities which have an agency, a branch or a subsidiary in Brazil.

Keywords: Nationality - Legal entities - Foreign companies

\section{INTRODUCTION}

La personne morale est un important sujet d'étude du droit international privé et public. Il y a plusieurs exemples de cette convergence, comme le cas Barcelona Traction, décidé par la Cour Internationale de Justice de la Haye ${ }^{1}$, les divers traités bilatéraux pour éviter la double imposition et ceux qui garantissent la protection réciproque des investissements. D'ailleurs, chaque fois de plus, il y a moins de différences entre ces deux branches du droit ${ }^{2}$.

L'objectif de cet article est de faire une brève analyse du droit international privé brésilien et de ses quatre grands sujets d'étude (la nationalité, le statut des étrangers, le conflit des lois et le conflit des juridictions) concernant la personne morale, ce qui a des conséquences aussi dans le cadre du droit international public. Ainsi, l'article sera divisée en quatre chapitres, qui correspondent aux quatre grands sujets de la discipline.

\section{LA NATIONALITÉ DES PERSONNES MORALES}

Une question très importante est celle de déterminer la nationalité des personnes morales, car une société étrangère est celle qui n'a pas la nationalité locale. Dans ce domaine, il convient d'analyser les critères qui permettront la détermination de la nationalité des personnes morales. Il y en a plusieurs, dont les plus importants sont ceux: i) de l'incorporation; ii) du siège social; et iii) du contrôle. Citons-les.

Selon le critère de l'incorporation, la personne morale a la nationalité du pays où elle s'est constituée. C'est le critère en général adopté dans les pays du common law (en Angleterre et aux États-Unis, par exemple) 3 $^{3}$ Cette

1 Barcelona Traction, Light and Power Company, Limited ,arrêt, C.I.J. Recueil 1970.

2 Andreas F. Lowenfeld, Public law in the international arena: conflict of laws, international law, and some suggestions for their interaction / by Andreas F. Lowenfeld. Recueil des cours, Volume 163 (1979-II), p.321: «My first message, at least at a personal level, is that, the study and practice of private international law is highly relevant to the study and practice of public international law - and vice versa».

3 Cf. sur la question: Jacob Dolinger et Carmen Tiburcio, Direito Internacional Privado: parte geral e processo internacional. Rio de Janeiro: Forense, 2016, p. 246; Henri Battifol et Paul Lagarde, Droit International Privé, t. 1, 6.ed. Paris: Librairie générale et de jurisprudence, 1974, p. 254. V. aussi, sur le modèle adopté aux États-Unis et en Anglaterre: Restatement Second, Conflict of Laws, 297; A. V. Dicey et J. H. C. Morris, The Conflict of Laws, 8. ed. Londres: 
méthode est critiqué, toutefois, à cause de son trait formaliste, qui permet aux fondateurs de choisir, de manière arbitraire et voir abusive, la nationalité et, par conséquent, la loi qui régira le statut juridique de l'entreprise 4 .

En effet, ce critère tend à stimuler la fraude. Ainsi, si la nationalité de la personne morale est définie uniquement à partir du lieu de son incorporation, les étrangers pourront exercer des activités réservées aux nationaux sous couvert d'une personne morale localement créée 5 . Le critère doit être tempéré. Plus récemment, toutefois, on constate que le critère de l'incorporation a gagné importance à cause du droit communautaire. L'article 58 du Traité $\mathrm{CE}^{6}$ détermine que les entreprises constituées dans l'un des États membres auront la nationalité de celui-ci, à condition qu'elles aient leur siège réel dans un autre État-membre. L'État du siège est obligé à reconnaître et à permettre que l'entreprise jouisse de droits sur son territoire si l'État où elle a été constituée la lui reconnaît.

Les nouvelles législations de droit international privé des pays de l'Europe tendent à adopter le critère de l'incorporation. Ainsi, par exemple, la loi suisse de $1987^{7}$ et la loi italienne de $1995^{8}$.

Stevens \& Sons Limited, 1967, règle n 70.

4 Jean Derruppé, Droit International Privé, 5.ed. Paris: Dalloz, 1978, p. 40.

5 Sur le thème, Henri Battifol et Paul Lagarde, Droit International Privé, t. 1, 6.ed. Paris: Librairie générale et de jurisprudence, 1974, p. 254: «Les Anglo-saxons vont d'ailleurs plus loin en CE sens par le système de $<$ l'incorporation $>$ : société est régie par la loi du lieu où les formalités de constitution ont été accomplies, même si le siège social réel est dans un autre pays. Le système donne aux associés la latitude de conserver le bénéfice de la loi anglaise et de la protection diplomatique anglaise quel que soit le lieu de leur activité, tout en évitant les discussions éventuelles sur la localisation du siège réel. Mais la liberté qu'assure ce formalisme est jugée dangereuse pour l'autorité de la loi par les partisans du siège social dans les pays continentaux où les sociétés pourraient s'incorporer à Londres pour éluder les dispositions de la loi locale».

6 Traité instituant la Communauté Européenne signé à Rome le 25 mars 1957, article 58: «Les sociétés constituées en conformité de la législation d'un État membre et ayant leur siège statutaire, leur administration centrale ou leur principal établissement à l'intérieur de la Communauté sont assimilées, pour l'application des dispositions du présent chapitre, aux personnes physiques ressortissantes des États membres.

Par sociétés, on entend les sociétés de droit civil ou commercial, y compris les sociétés coopératives, et les autres personnes morales relevant du droit public ou privé, à l'exception des sociétés qui ne poursuivent pas de but lucratif».

7 Loi fédérale n 291, du 18 décembre 1987, art. 154 : « 1. Les sociétés sont régies par le droit de l'Etat en vertu duquel elles sont organisées si elles répondent aux conditions de publicité ou d'enregistrement prescrites par ce droit ou, dans le cas où ces prescriptions n'existent pas, si elles se sont organisées selon le droit de cet Etat.

2. La société qui ne remplit pas ces conditions est régie par le droit de l'Etat dans lequel elle est administrée en fait ».

8 Legge 31 maggio 1995, n 218, art. 25: «Le società, le associazioni, le fondazioni ed ogni altro ente, pubblico o privato, anche se privo di natura associativa, sono disciplinati dalla legge dello Stato nel cui territorio è stato perfezionato il procedimento di costituzione. Si applica, tuttavia, la legge italiana se la sede dell'amministrazione è situata in Italia, ovvero se in Italia si trova 
D'autre, le critère du siège social détermine que la personne morale aura la nationalité du pays où se trouve son siège. Ceux qui soutiennent l'adoption de ce critère affirment que la personnalité et la capacité d'une entreprise se lient à ses activités; c'est la loi du pays de son siège social la plus adéquate pour déterminer les conditions que la personne morale devra remplir pour être reconnue dans tout le monde 9 Ce critère établit un lien effectif et objectif entre la personne morale et la loi applicable. En plus, il protège les intérêts des tiers ayant des relations avec la société et qui ne doivent pas être surpris par l'application d'une loi étrangère. C'est le critère adopté en droit commun français.

Ainsi, pour la détermination de la nationalité française des sociétés, on conjugue les critères du siège social avec celui du siège réel. L'article1837, première partie, du Code Civil français établit: «Toute société dont le siège est situé sur le territoire français est soumise aux dispositions de la loi française». La partie finale de l'article, toutefois, détermine que «Les tiers peuvent se prévaloir du siège statutaire, mais celui-ci ne leur est pas opposable par la société si le siège réel est situé en un autre lieu» ${ }^{10}$. Cette règle a été bilatéralisée par la jurisprudence.

Dans plusieurs cas où une entreprise se constituait à l'étranger pour échapper à l'application de la loi française, la jurisprudence française a toujours été très dure, en précisant que c'est le siège réel et non le siège statutaire qui détermine la loi applicable aux sociétés (la doctrine cite, par exemple, un arrêt du 21 novembre 1889, de la chambre Criminelle de la Cour de Cassation). Cette manœuvre a toujours été l'un des plus courants exemples que la doctrine française utilise pour

l'oggetto principale di tali enti».

9 Jacob Dolinger et Carmen Tiburcio, Direito Internacional Privado: parte geral e processo internacional. Rio de Janeiro: Forense, 2016, p. 246. V. aussi Henri Battifol et Paul Lagarde, Droit International Privé, t. 1, 6.ed. Paris: Librairie générale et de jurisprudence, 1974, p. 252 et 253 ; et Yvon Loussouarn et Jean-Denis Bredin, Droit du Commerce International. Paris : Sirey, 1969, p. 266 et 267.

10 Auparavant, l'article 3 de la loi du 24 juillet 1966 suivait la même orientation. Sur le thème, v. Henri Battifol et Paul Lagarde, Droit International Privé, t. 1, 6.ed. Paris: Librairie générale et de jurisprudence, 1974, p. 253 ; cf. aussi Yvon Loussouarn et Jean-Denis Bredin, Droit du Commerce International. Paris : Sirey, 1969, p. 254, note (2): «Les articles 31 et 60 de la loi du 24 juillet 1966, le premier relatif aux sociétés en commandite simple, et le second aux sociétés à responsabilité limitée, disposent que $<$ Les associés ne peuvent, si ce n'est à l'unanimité changer la nationalité de la société>. Quant à l'article 154 de la loi du 24 juillet 1966, il prévoit, reprenant en substance la disposition de l'ordonnance du 7 janvier 1959 que l'assemblée générale des actionnaires peut changer la nationalité de la société à condition que le pays d'accueil ait conclu avec la France une convention spéciale, permettant d'acquérir sa nationalité et de transférer le siège social et conservant à la société sa personnalité juridique». 
expliquer le phénomène de la fraude à la loi ${ }^{11,12}$.

Au-delà de la France, le siège social est aussi le critère traditionnellement adopté par tous les pays de l'Europe continentale occidentale, à l'exception des Pays-Bas ${ }^{13}$. Comme on verra ensuite, c'est le critère partiellement adopté au Brésil pour déterminer la nationalité brésilienne des sociétés anonymes.Le troisième critère, cette du contrôle, détermine que la personne morale aura la même nationalité que celle des personnes qui la contrôlent - autrement dit, des personnes qui détiennent la majorité de son capital. C'est l'idée de «perce de la voie sociale» ${ }^{14}$. Ce critère a été largement adopté pendant les Grandes Guerres pour identifier les sociétés contrôlées par les ennemis ${ }^{15}$.

Il présente, toutefois, plusieurs difficultés, du fait que les titres des sociétés peuvent changer de mains très facilement (ce qui pourrait conduire à un constant changement de nationalité de la personne morale) et aussi du fait que les sociétés peuvent, elles-mêmes, être contrôlées par d'autres sociétés, ce qui augmente la difficulté ${ }^{16}$.

De plus, il n'y a pas nécessairement un lien important entre la nationalité des actionnaires et les règles relatives au fonctionnement de la société. Aujourd'hui, ce critère n'est guère adopté, sauf pour restreindre quelques droits à des sociétés qui, bien qu'établies dans un certain pays, sont contrôlées par des étrangers. Le but est d'empêcher

11 Cf. Henri Battifol et Paul Lagarde, Droit International Privé, t. 1, 6.ed. Paris: Librairie générale et de jurisprudence, 1974, p. 255. V. Crim. 21 nov.1889, S. 97.1.84, J. 89.850; Req. 22 déc. 1896, D.P. 97.1.159, S. 97.1.84 ; Crim. 4 août 1906, J. 1907.151 ; Paris, 27 mars 1907, J. 1907.768, G.P. 1907.1.496 ; Trib. Lille, 21 mai 1908 ; Aix, 6 juil. 1908, G.P. 1908.2.462 ; Paris, 23 mars 1909, D.P. 1910.2.108, S. 1909.2.183, R. 1909.877. 11 et 25 avril 1913, G.P. 1913.2.185 ; Angers, 23 juin 1913, G.P. 1913.2.113 ; Rennes, 1er mars 1914, Rec. Nantes, 1914.1.250 ; Paris, 17 déc.1919, G.P. 1920.1.34 ; Paris, 10 nov. 1922, S. 1922.2.128, J. 1923.320 ; Rennes, 26 juil. 1926, G.P. 1927.1.59 ; Paris, 4 févr. 1935, R. 1935.816 ; Seine, 25 oct. 1943, G.P. 1944.1.8 ; Paris 31 oct. 1957, R. 1958.345, note Y.L. Sur l'éffectivité du siège social en matière fiscale dans l'Union française Com., 25 avril 1950, R. 1951.291, note Y.L. Sur la faillite des sociétés Cass., 15 juil. 1954, G.P., 1954.2.234 ; 19 mars 1956, D. 1956.351 ; 15 juin 1957, D.1957.596.

12 Pour comprendre le choix de la jurisprudence française pour le critère du siège social, v. Jean Schapira, Le Droit International des Affaires. Paris: Presses Universitaires de France, 1972, p. 57. 13 V. Yvon Loussouarn et Jean-Denis Bredin, Droit du Commerce International. Paris: Sirey, 1969, p. 496, 497 et 498. Cf. aussi Jacob Dolinger et Carmen Tiburcio, Direito Internacional Privado: parte geral e processo internacional. Rio de Janeiro: Forense, 2016, p. 246 et 247.

14 Jacob Dolinger et Carmen Tiburcio, Direito Internacional Privado: parte geral e processo internacional. Rio de Janeiro: Forense, 2016, p. 249 V. Henri Battifol et Paul Lagarde, Droit International Privé, t. 1, 6.ed. Paris: Librairie générale et de jurisprudence, 1974, p. 258 ; et Yvon Loussouarn et Jean-Denis Bredin, Droit du Commerce International. Paris: Sirey, 1969, p. 265 et 266.

15 Sur le thème, Jacob Dolinger et Carmen Tiburcio, Direito Internacional Privado: parte geral e processo internacional. Rio de Janeiro: Forense, 2016, p. 249 et 250.

16 Jacob Dolinger et Carmen Tiburcio, Direito Internacional Privado: parte geral e processo internacional. Rio de Janeiro: Forense, 2016, p. 250. 
l'influence étrangère dans des affaires stratégiques ${ }^{17}$.

Ainsi, par exemple, au Brésil, l'article 171 de la Constitution Fédérale de 1988, déjà abrogé ${ }^{18}$, faisait une distinction entre les entreprises brésiliennes de capital national et les entreprises brésiliennes de capital étranger ${ }^{19}$.

Le Code Bustamante ${ }^{20}$, diplôme conventionnel élaboré en 1928 et adopté par plusieurs pays en Amérique, détermine, dans ses articles 16 et 17, que les corporations, fondations et associations auront la nationalité du pays où elles ont été créées (critère de l'incorporation) ${ }^{21}$. En ce qui concerne les sociétés civiles, commerciales et industrielles, l'article 18 du Code détermine qu'elles auront la nationalité qui est stipulée dans leur statut social (c'est le critère de l'autonomie de la volonté) ou, en son absence, celle du lieu où se situe habituellement son organe de direction principal (critère du siège social) ${ }^{22}$.

Quant aux sociétés anonymes, l'article 19 du Code Bustamante établit que leur nationalité sera déterminée par son contrat social (critère de l'autonomie de la volonté) et, éventuellement, par la loi du lieu où normalement se réunit l'assemblée générale des actionnaires, ou encore,

17 Jacob Dolinger et Carmen Tiburcio, Direito Internacional Privado: parte geral e processo internacional. Rio de Janeiro: Forense, 2016, p. 250: «Modernamente, o critério do controle quase não é mais utilizado para aferir a nacionalidade, mas a ele se tem recorrido para negar certos direitos a sociedades estabelecidas no país que, por estarem sob controle de estrangeiros, não devem ter reconhecida a condição de sociedade nacional para determinadas atividades e para certos privilégios»».

18 Amendement à la Constitution n 6/1995.

19 La Constitution brésilienne disposait, dans son article 171, déjà abrogé: «São consideradas: I - empresa brasileira a constituída sob as leis brasileiras e que tenha sua sede e administração no País; II - empresa brasileira de capital nacional aquela cujo controle efetivo esteja em caráter permanente sob a titularidade direta ou indireta de pessoas físicas domiciliadas e residentes no País ou de entidades de direito público interno, entendendo-se por controle efetivo da empresa a titularidade da maioria de seu capital votante e o exercício, de fato e de direito, do poder decisório para gerir suas atividades. $§ 1$ - A lei poderá, em relação à empresa brasileira de capital nacional: I - conceder proteção e benefícios especiais temporários para desenvolver atividades consideradas estratégicas para a defesa nacional ou imprescindíveis ao desenvolvimento do País; II - estabelecer, sempre que considerar um setor imprescindível ao desenvolvimento tecnológico nacional, entre outras condições e requisitos: a) a exigência de que o controle referido no inciso II do caput se estenda às atividades tecnológicas da empresa, assim entendido o exercício, de fato e de direito, do poder decisório para desenvolver ou absorver tecnologia; b) percentuais de participação, no capital, de pessoas físicas domiciliadas e residentes no País ou entidades de direito público interno. $\S 2$ - Na aquisição de bens e serviços, o Poder Público dará tratamento preferencial, nos termos da lei, à empresa brasileira de capital nacional».

20 Pour une analyse plus détaillée du Code Bustamante, v. Antonio S. de Bustamante y Sirven, Derecho Internacional Privado, v. I, p. 247, 248, 300 et 301.

21 Jacob Dolinger et Carmen Tiburcio, Direito Internacional Privado: parte geral e processo internacional. Rio de Janeiro: Forense, 2016, p. 252.

22 Dans le même sens, v. Jacob Dolinger et Carmen Tiburcio, Direito Internacional Privado: parte geral e processo internacional. Rio de Janeiro: Forense, 2016, p. 252. 
en son absence, par la loi du lieu où fonctionne son principal Conseil d'Administration ou son principal organe directif (critère du siège social) ${ }^{23}$. Malgré sa valeur historique et bien qu'il ait été ratifié par plusieurs pays américains, le Code Bustamante n'est guère utilisé en jurisprudence.

Il y a deux Conventions qui ont été élaborées au sein des Conférences Spécialisées Interaméricaines en Droit International Privé de l'Organisation des États Américains: la Convention sur le Conflit de Lois relatives aux Sociétés Commerciales, élaborée en 1979 à Montevidéo (à l'Uruguay); et la Convention sur la Personnalité et Capacité des Personnes Morales en Droit International Privé, élaborée en 1984 à La Paz (en Bolivie) ${ }^{24}$.

Toutes les deux ne mentionnent pas la nationalité des personnes morales mais seulement la loi qui leur est appliquée, dans le domaine du conflit des lois. La Convention de la Haye de 1956 Concernant la Reconnaissance de la Personnalité Juridique des Sociétés, Associations et Fondations Étrangères utilise le même critère.

Qu'en est-il du droit commun brésilien? L'article 11 de la Loi d'Introduction aux Normes du Droit Brésilien, de 1942, conjugué avec les articles 19 et 21 de l'ancienne Introduction au Code Civil, de 1916, consacre le critère de l'incorporation ${ }^{25}$.

23 Cf. Jacob Dolinger et Carmen Tiburcio, Direito Internacional Privado: parte geral e processo internacional. Rio de Janeiro: Forense, 2016, p. 252.

24 La Convention sur le Conflit de Lois relatives aux Sociétés Commerciales, élaborée en 1979 à Montevidéo a été internalisée au Brésil par le Décret n. 2400, du 21 novembre 1997; et la Convention sur la Personnalité et Capacité des Personnes Morales en Droit International Privé, élaborée en 1984 à La Paz a été internalisée au Brésil par le Décret n. 2427, du 17 décembre 1997. Sur les deux Conventions, v. Jacob Dolinger et Carmen Tiburcio, Direito Internacional Privado: parte geral e processo internacional. Rio de Janeiro: Forense, 2016, p. 252 et 253.

25 Sur la conjugaison de l'article 11 de la Loi d'Introdution aux Normes du Droit Brésilien, de 1942, avec les articles 19 et 21 de l'Introdution au Code Civil de 1916, v. Jacob Dolinger et Carmen Tiburcio, Direito Internacional Privado: parte geral e processo internacional. Rio de Janeiro: Forense, 2016, p. 258 et 259: «Para compreender o sistema brasileiro das pessoas jurídicas no plano internacional, há de se examinar sua evolução, coordenando o disposto nos sucessivos dois diplomas de DIP: de 1916 e de 1942».

A Introdução do Código Civil de 1916 dispunha que <são reconhecidas as pessoas jurídicas estrangeiras $>$ (artigo 19) e que $<$ a lei nacional das pessoas jurídicas determina-lhes a capacidade $>$ (artigo 21). Reconhecida a pessoa jurídica, passa ela a ter capacidade, tudo na conformidade de sua lei nacional.

Não tinha, contudo, o legislador do Código Civil determinado o critério para aferição da nacionalidade da pessoa jurídica, o que só veio a ser estabelecido pela Lei de Introdução de 1942, que em seu artigo 11, dispõe que < as organizações destinadas a fins de interesse coletivo, como as sociedades e as fundações, obedecem à lei do Estado em que se constituírem>.

Melhor teria andado o legislador se tivesse referido simplesmente às pessoas jurídicas como o fizera a Introdução de 1916. De qualquer forma, o dispositivo da atual Lei deve ser entendido como uma complementação interpretativa do texto de 1916, que deixara de definir o critério a ser aplicado para determinação da lei nacional da pessoa jurídica. 
On analysera ces articles par la suite, lorsqu'on traite de la personne morale et les conflits de lois. La loi des sociétés anonymes prévoit une règle spéciale. C'est l'article 60 du Décret-loi n 2.627 de 1940, qui dispose que «sont nationales les sociétés organisées en conformité avec la loi brésilienne et qui ont leur siège d'administration au pays». Cet article a été expressément maintenu par l'article 300 de la Loi des Sociétés Anonymes de $1976^{26}$.

Pour qu'une société anonyme ait la nationalité brésilienne, elle devra avoir son siège au Brésil et y être constituée ${ }^{27}$. Cette règle a été étendue pour déterminer la nationalité brésilienne des entreprises en général, pas seulement pour des sociétés anonymes ${ }^{28}$. Maintenant la question est traitée par l'article 1126 du Code Civil de $2002^{29}$.

Pour les sociétés anonymes étrangères, ou pour toutes les autres personnes morales étrangères, c'est l'article 11 de la Loi d'Introduction aux Normes du Droit Brésilien - qui consacre le critère de l'incorporation - qui s'applique ${ }^{30}$.

Conclui-se da justaposição das duas leis introdutórias que o reconhecimento da personalidade e a determinação da capacidade das pessoas jurídicas no Direito Internacional Privado brasileiro decorre da lei de sua nacionalidade e que esta é determinada pelo país de sua constituição, sistema idêntico ao britânico».

26 L'article 60 du Décret-loi n 2.627 de 1940 a causé des perpléxités dans la doctrine, qui posait des questions à propos d'une possible antinomie entre cet article et l'article 11 de la Loi d'Introdution aux Normes du Droit Brésilien, de 1942. Mais l'antinomie a été écartée, cf. Miguel Maria de Serpa Lopes, Comentário Teórico e Prático da Lei de Introdução ao Código Civil, v. III. Rio de Janeiro: Livraria Jacintho, 1946, p. 171. V. aussi Jacob Dolinger et Carmen Tiburcio, Direito Internacional Privado: parte geral e processo internacional. Rio de Janeiro: Forense, 2016, p. 259 et 260.

27 Jacob Dolinger et Carmen Tiburcio, Direito Internacional Privado: parte geral e processo internacional. Rio de Janeiro: Forense, 2016, p.260; Jacob Dolinger, “A Sociedade Anônima Brasileira - Critério Determinador de sua Nacionalidade", Revista de Direito Mercantil, Industrial, Econômico e Financeiro, vol. 23, p. 65 et suivantes. Cf. aussi Luiz Mélega, «Nacionalidade das Sociedades por Ações», Revista de Direito Mercantil, Industrial, Econômico e Financeiro, vol. 33, p. 127 et suivantes.

28 Jacob Dolinger et Carmen Tiburcio, Direito Internacional Privado: parte geral e processo internacional. Rio de Janeiro: Forense, 2016, p. 260.

29 Code Civil, 2002, Art. 1.126: «É nacional a sociedade organizada de conformidade com a lei brasileira e que tenha no País a sede de sua administração».

30 Miguel Maria de Serpa Lopes, Comentário Teórico e Prático da Lei de Introdução ao Código Civil, v. III. Rio de Janeiro : Livraria Jacintho, 1946, p. 171. Cf. aussi Jacob Dolinger et Carmen Tiburcio, Direito Internacional Privado: parte geral e processo internacional. Rio de Janeiro: Forense, 2016, p. 261 514: «Assim, uma sociedade constituída na Espanha, que estabeleça sua sede social em Portugal, será considerada por nosso DIP. sociedade espanhola. Mas a sociedade constituída no Brasil que não estabelecer aqui sua sede social não será considerada brasileira, o que nos leva, em um passo mais adiante, a compreender que nossas autoridades não registrarão uma sociedade no Brasil que não fixe sua sede social em território brasileiro». 


\section{LE STATUT DES ENTREPRISES ÉTRANGÈRES}

Bien que les entreprises étrangères soient reconnues d'après la loi de leur nationalité, pour exercer certaines activités au Brésil, comme on l'a déjà mentionné, il faudra respecter aussi la loi brésilienne. Ce n'est pas, toutefois, une condition pour reconnaître la personnalité juridique de l'entreprise étrangère, mais pour lui permettre la jouissance de certains droits au Brésil.

La règle, dans un État de Droit, c'est que toute personne est libre pour exercer tout type d'activité privée licite. C'est le principe de la libre initiative, consacrée au niveau constitutionnel ${ }^{31}$. Cependant, il y a quelques restrictions imposées aux entreprises étrangères au Brésil. Ces restrictions parfois se rapportent aux entreprises étrangères elles-mêmes, parfois à la participation des personnes étrangères dans des sociétés brésiliennes. Citons-en quelques-unes ${ }^{32}$.

\section{- La Constitution interdit les personnes étrangères d'être propriétaires de moyens de communication (article 222) ${ }^{33}$ et d'obtenir des concessions pour explorer des ressources minérales et hydriques}

31 Le príncipe de la libre initiative est consacré aux articles 1er et 170 de la Constitution brésilienne. Le 1er article de la Constitution a la rédaction suivante: «A República Federativa do Brasil, formada pela união indissolúvel dos Estados e Municípios e do Distrito Federal, constitui-se em Estado Democrático de Direito e tem como fundamentos: I - a soberania; II - a cidadania; III - a dignidade da pessoa humana; IV- os valores sociais do trabalho e da livre iniciativa; V - o pluralismo político. Parágrafo único. Todo o poder emana do povo, que o exerce por meio de representantes eleitos ou diretamente, nos termos desta Constituição». L'article 170 dispose: «A ordem econômica, fundada na valorização do trabalho humano e na livre iniciativa, tem por fim assegurar a todos existência digna, conforme os ditames da justiça social, observados os seguintes princípios: I - soberania nacional; II - propriedade privada; III - função social da propriedade; IV - livre concorrência; V - defesa do consumidor; VI - defesa do meio ambiente, inclusive mediante tratamento diferenciado conforme o impacto ambiental dos produtos e serviços e de seus processos de elaboração e prestação; VII - redução das desigualdades regionais e sociais; VIII - busca do pleno emprego; IX - tratamento favorecido para as empresas de pequeno porte constituídas sob as leis brasileiras e que tenham sua sede e administração no País. Parágrafo único. É assegurado a todos o livre exercício de qualquer atividade econômica, independentemente de autorização de órgãos públicos, salvo nos casos previstos em lei».

32 Pour un panorama du status des entreprises étrangères au Brésil, v. Carmen Tiburcio, A condição jurídica do estrangeiro na Constituição brasileira de 1988. In: Daniel Sarmento, Daniela Ikawa e Flávia Piovesan (orgs.), Igualdade, diferença e direitos humanos, 2008, p.747. V. aussi: Carmen Tiburcio et Luís Roberto Barroso, Direito Constitucional Internacional, Rio de Janeiro: Renovar, 2013, p. 297-318.

33 Jacob Dolinger et Carmen Tiburcio, Direito Internacional Privado: parte geral e processo internacional. Rio de Janeiro: Forense, 2016, p. 266,267 et 268. V. aussi José Afonso da Silva, Comentário Contextual à Constituição. São Paulo: Malheiros, 2010, p. 848 et 849. 
(article 176, $\S 1)^{34}$.

- La Loi 5.709 de 1971 impose des restrictions aux personnes morales étrangères pour l'acquisition des immeubles ruraux ${ }^{35}$.

- La Loi 6.634 de 1979 interdit aux personnes morales étrangères d'être actionnaires dans des entreprises brésiliennes qui soient titulaires de droit réel sur des immeubles situés dans la zone de frontière ${ }^{36}$.

Enfin, toutes ces restrictions se justifient par face à la préoccupation de protection des intérêts nationaux. Elles se rapportent à des activités que le législateur considère essentielles et stratégiques, de manière que, si leur exercice était librement attribué à une entreprise contrôlée par des étrangers, les intérêts du pays pourraient être menacés ${ }^{37}$.

34 Jacob Dolinger et Carmen Tiburcio, Direito Internacional Privado: parte geral e processo internacional. Rio de Janeiro: Forense, 2016, p. 269. Cf. José Afonso da Silva, Comentário Contextual à Constituição. São Paulo: Malheiros, 2010, p. 741 et 742.

35 Par exemple, l'article 7ème de la Loi 5.709, de 1971, détermine: «A aquisição de imóvel situado em área considerada indispensável à segurança nacional por pessoa estrangeira, física ou jurídica, depende do assentimento prévio da Secretaria-Geral do Conselho de Segurança Nacional».

36 L'article 2 de la Loi 6.634, de 1979, prévoit: «Salvo com o assentimento prévio do Conselho de Segurança Nacional, será vedada, na Faixa de Fronteira, a prática dos atos referentes a: (...) V - transações com imóvel rural, que impliquem a obtenção, por estrangeiro, do domínio, da posse ou de qualquer direito real sobre o imóvel; VI - participação, a qualquer título, de estrangeiro, pessoa natural ou jurídica, em pessoa jurídica que seja titular de direito real sobre imóvel rural; (...)». En 2015, cette Loi a été alterée et une exception a été inclue «§ 4o.Excetuase do disposto no inciso $\mathrm{V}$, a hipótese de constituição de direito real de garantia em favor de instituição financeira, bem como a de recebimento de imóvel em liquidação de empréstimo de que trata o inciso II do art. 35 da Lei no 4.595 , de 31 de dezembro de 1964».

37 Toutefois, la doctrine reconnaît que les personnes morales étrangères dont la personnalité juridique est reconnue, dans le silence des textes sur leur statut en France, ont les mêmes droits des personnes morales françaises. Cf. Henri Battifol et Paul Lagarde, Droit International Privé, t. 1, 6.ed. Paris: Librairie générale et de jurisprudence, 1974, p. 269: «C'est dire qu'elles seront assimilées aux sociétés françaises, sauf texte contraire, puisque tel est aujoud'hui le principe pour l'étranger personne physique». Selon Yvon Loussouarn et Jean-Denis Bredin: «On s'accorde à admettre que les sociétés étrangères reconnues ont l'aptitude à jouir, en France, des mêmes droits que les sociétés françaises. En l'absence d'un texte exprès prévoyant cette assimilation, la jurisprudence a étendu aux personnes morales le principe d'assimilation admis pour les personnes physiques, et résultant de l'interprétation libérale de l'article $11 \mathrm{du}$ Code civil» (Yvon Loussouarn et Jean-Denis Bredin, Droit du Commerce International. Paris: Sirey, 1969, p. 328). 


\section{LES PERSONNES MORALES ET LES CONFLITS DE LOIS}

Pour être universellement reconnue, la personne morale devra remplir les conditions que le pays de sa nationalité lui impose pour acquérir la personnalité juridique. En règle, c'est la loi du pays de la nationalité de la personne morale qui régira son statut juridique, c'està-dire sa capacité juridique pour contracter des obligations et pour acquérir des droits dans tout le monde (c'est la lex societatis). Il faut distinguer, toutefois, la reconnaissance de l'entreprise étrangère et son aptitude pour s'installer au Brésil. Ces deux aspects seront soumis à des lois différentes.

En ce qui concerna la question de la reconnaissance de la personne morale étrangère, l'ancienne Introduction au Code Civil de 1916 déterminait, dans son article 19, que «sont reconnues les personnes morales étrangères».

De plus, l'article 21 disposait que «la loi national des personnes morales détermine leur capacité». C'était la consécration de l'application de la lex societatis, mais le législateur n'indiquait pas le critère adopté pour indiquer quelle était la nationalité des personnes morales.

En 1942, la Loi d'Introduction au Code Civil est entrée en vigueur. Celle-ci régit le droit international privé brésilien jusqu'aujourd'hui, sous la dénomination de Loi d'Introduction aux Normes du Droit Brésilien. Son article 11 établit que «les organisations destinées à des buts collectifs, ainsi que les sociétés et les fondations, obéissent à la loi d'État où elles se sont constituées». C'est la consécration du critère de l'incorporation, en suivant le modèle du droit anglais et nord-américain.

La doctrine recommande que l'article 11 de la Loi d'Introduction doit être compris comme un complément aux articles 19 et 21 de l'ancienne Introduction, de manière que le droit brésilien reconnaît les personnes morales étrangères, à condition qu'elles soient reconnues selon la loi du pays où elles ont été constituées.

Il faut dire que la Loi d'Introduction aux Normes du Droit Brésilien de 1942 a une règle, à l'article $16^{38}$, interdisant expressément le renvoi. Cela signifie que, dans le cas où une entreprise dont le siège social se situe au Brésil - mais qui a été constituée en France -, la règle de conflit brésilienne déterminera l'application de la loi française (critère de l'incorporation) et on ne fera pas jouer le renvoi de la loi française à la loi brésilienne (critère du siège social ${ }^{39}$ ).

38 Loi d'Introduction aux Normes du Droit Brésilien, 1942, art. 16: «Quando, nos termos dos artigos precedentes, se houver de aplicar a lei estrangeira, ter-se-á em vista a disposição desta, sem considerar-se qualquer remissão por ela feita a outra lei».

39 Jean Derruppé, Droit International Privé, 5.ed. Paris: Dalloz, 1978, p. 39: «Pour déterminer la loi applicable à la constituition et fonctionnement de la société, la doctrine française accepte unanimement de se réferer au siège social. C'est cette solution que l'article 3 de la loi du 
Somme toute, une entreprise étrangère dont la personnalité juridique est reconnue par le pays de son incorporation pourra célébrer un contrat au Brésil, être en justice devant le Pouvoir Judiciaire brésilien et également être actionnaire d'une société anonyme brésilienne (conformément à la partie finale de l'article 1.134 du Code Civil ${ }^{40}$ ).

Nonobstant, pour s'établir au pays, le respect à la lex societatis ne suffira pas. Il convient d'analyser aussi la loi appliquée pour qu'une entreprise étrangère puisse exercer des activités au Brésil en caractère permanent.

Comme on a mentionné auparavant, il faut distinguer la reconnaissance de la personne morale étrangère de son aptitude pour fonctionner au Brésil. Tandis que sa reconnaissance dépend exclusivement da la lex societatis, son aptitude pour fonctionner au Brésil dépendra aussi des conditions imposées par la loi brésilienne.

D'où la règle du paragraphe unique de l'article 11, qui détermine que les personnes morales «ne pourront pas, toutefois, avoir, au Brésil, filiale, agence ou établissement avant que ses actes constitutifs soient approuvés par le Gouvernement brésilien, étant soumises à la loi brésilienne».

Aussi pour les sociétés anonymes nous avons une règle spécifique semblable. L'article 68 du Décret-loi 2.627, de 1940, détermine que «les sociétés anonymes étrangères autorisées à fonctionner seront soumises aux lois et aux tribunaux brésiliens en ce qui concerne les actes et opérations qu'elles pratiquent au Brésil». C'est l'application du principe selon lequel l'État d'accueil peut toujours réglementer l'exercice des activités dans son pays. Le Code Civil de 2002 reprend cette règle ${ }^{41}$.

Il faut remarquer que les personnes morales étrangères peuvent exercer leurs activités au Brésil de deux manières: i) constitution d'une filiale au Brésil et dans ce cas-là elle subira les restrictions imposées pour les personnes morales étrangères; et ii) constitution d'une entreprise indépendante au Brésil avec personnalité juridique propre, c'est-à-dire une personne morale brésilienne qui sera traité comme telle, indépendamment du fait qu'elle soit contrôlée par une entreprise étrangère ${ }^{42}$.

24 juillet 1966 a consacré». (Loi n 66-537 du 24 juillet 1966, art. 3 : «Les sociétés dont le siège social est situé en territoire français sont soumises à la loi française. Les tiers peuvent se prévaloir du siège statutaire, mais celui-ci ne leur est pas opposable par la société si son siège réel est situé en un autre lieu»).

40 Code Civil, 2002, art. 1.134: «A sociedade estrangeira, qualquer que seja o seu objeto, não pode, sem autorização do Poder Executivo, funcionar no País, ainda que por estabelecimentos subordinados, podendo, todavia, ressalvados os casos expressos em lei, ser acionista de sociedade anônima brasileira».

41 Code Civil, 2002, Art. 1.137:«A sociedade estrangeira autorizada a funcionar ficará sujeita às leis e aos tribunais brasileiros, quanto aos atos ou operações praticados no Brasil».

42 L'article 64 du Décret-loi 2627 de 1940 dit «As sociedades anônimas ou companhias estrangeiras, qualquer que seja o seu objeto, não podem, sem autorização do Governo Federal, funcionar no país, por si mesmas, ou por filiais, sucursais, agências, ou estabelecimentos que as representem, podendo, todavia, ressalvados os casos expressos em lei, ser acionistas de 
Il convient d'analyser la question de la loi appliquée aux obligations des personnes morales et chez nous c'est controversée la possibilité pour les entreprises de choisir la loi appliquée aux contrats.

L'article 13 de l'ancienne Introduction au Code Civil de 1916 disposait : «Sauf stipulation contraire, la substance et les effets des obligations seront réglés par la du lieu où elles ont été contractées». Ce dispositif, lorsqu'il disait «sauf stipulation contraire», consacrait l'application du principe de l'autonomie de la volonté aux relations contractuelles, c'est-à-dire, la même règle de conflit qui est adoptée dans les systèmes de droit international privé les plus modernes.

À propos, c'est le critère adopté en France dès l'arrêt American Trading, de 1910, selon lequel «loi applicable aux contrats, soit en ce qui concerne leur formation, soit quant à leurs effets et conditions, est celle que les parties ont adoptée» ${ }^{43}$.

L'article 9 de la Loi d'Introduction aux Normes du Droit Brésilien, de 1942, toutefois, n'a pas reproduit expressément cette règle. Il détermine que «pour qualifier et régir les obligations, la loi du pays où elles se sont constituées sera appliquée». Ainsi, la littéralité de l'article semble avoir consacré le critère de l'application de la lex celebrationis, sans espace pour l'application du critère de l'autonomie de la volonté.

Selon le texte de l'article, les parties contractantes ne peuvent pas choisir la loi qui y sera appliquée. Dans cette matière, la doctrine se divise. L'entendement d'une partie de la doctrine va dans le même sens de la lettre de l'article 9. Comme la loi de 1942 n'a pas reproduit l'expression «sauf stipulation contraire», contenue dans l'ancien article 13 de l'Introduction de 1916, on comprend que l'intention du législateur a été d'abolir l'application du critère de l'autonomie de la volontét4.

Toutefois, l'autre partie de la doctrine affirme que la choix de la loi applicable au contrat n'a pas été interdit par la loi de $1942^{45}$. Une

sociedade anônima brasileira». Cette exception a été motif de sévère critique du juriste Haroldo Valladão, qui se demande comment on peut autoriser que la société étrangère s'infiltre dans l'économie du pays par acquisition du capital d'une société anonyme bresilienne si la société étrangère seulement peut fonctionner au Brésil avec l'autorisation du gouvernment, qui est antécédé d'un rigoureux examen des documents. (cf. Haroldo Valladão, Direito Internacional Privado. Rio de Janeiro: Freitas Bastos. 1980. p. 461).

43 Jean Derruppé, Droit International Privé, 5.ed. Paris: Dalloz, 1978, p. 54 : «Les contrats sont soumis à la loi choisie par les parties (Loi d'autonomie)».

44 Dans ce sens, Nadia de Araújo, qui s'est manifestée contre l'autonomie de la volonté, a écrit: «No Brasil, a regra de conexão utilizada para os contratos internacionais é a lex loci contractus, na forma estabelecida pelo art. $9^{\circ}$ da Lei de Introdução ao Código Civil, de cuja exegese não se extrai a permissão à teoria da autonomia da vontade, antes consagrada na Introdução ao Código Civil de 1916» (Nadia de Araújo, «Contratos Internacionais e a Jurisprudência Brasileira: Lei Aplicável, Ordem Pública e Cláusula de eleição de foro», In João Grandino Rodas, Contratos internacionais, 3.ed. São Paulo: Editora Revista dos Tribunais, 2002, p. 200).

45 Jacob Dolinger, Direito Internacional Privado (Parte Especial): Direito Civil Internacional, 
explication historique pour ça a été posée par le Professeur Haroldo Valladão, 1'un des plus importants juristes de droit international privé brésilien du XXe siècle. Il explique qu'en 1942 le Brésil était soumis à une dictature («le Nouvel État»). Ainsi, toute référence à l'autonomie de la volonté était vue avec des mauvais yeux et ne pouvait pas apparaître de manière expresse dans les lois ${ }^{46}$.

Selon Valladão, toutefois, le législateur de 1942 a consacré le critère de l'autonomie de manière cachée, lorsqu'il prévoit, dans le paragraphe second de l'article 9 de la Loi de 1942, que «l'obligation résultant du contrat est réputée constituée dans le lieu où réside le proposant ${ }^{47}$. Or, selon Valladão, l'utilisation du verbe «réputer» établit une présomption. Si les parties en disposent autrement, cette présomption sera écartée ${ }^{48}$.

Philadelpho de Azevedo, un ancien ministre de la Cour Suprême de la première moitié du XXe siècle, justifie l'admission du critère de l'autonomie de la volonté d'après le principe de la liberté contractuelle. Si les parties sont libres pour établir le contenu des clauses de son contrat, elles peuvent reproduire les dispositions d'une loi quelconque; ainsi, il n'y a rien qui les empêche, au lieu de reproduire toutes les dispositions de cette loi, d'y faire référence de manière générale. La liberté pour les parties de choisir la loi appliquée au contrat, d'après Azevedo, est comprise dans le principe de la liberté contractuelle ${ }^{49}$.

Le Professeur Lauro Gama a fait une relecture constitutionnelle de cet argument: toute restriction à la liberté des individus doit se

v. II. Rio de Janeiro: Renovar, 2002, p. 458: «Outrossim, o direito brasileiro sempre admitiu a interpretação teleológica da lei, e segundo esta, é indubitável que, considerada a realidade das relações jurídicas internacionais da atualidade, considerado o panorama do direito internacional privado contemporâneo, considerados os interesses da economia brasileira, em crescente internacionalização, que o artigo $9^{\circ}$ da LICC não impõe qualquer óbice à escolha de outra lei que a lex contractus». Cf. aussi: Jacob Dolinger et Carmen Tiburcio, Direito Internacional Privado: parte geral e processo internacional. Rio de Janeiro: Forense, 2016, p. 360: «Quanto à faculdade de as partes escolherem a lei aplicável a contrato internacional, apesar do silêncio do legislador, a melhor doutrina entende que essa escolha é aceita em nosso sistema jurídico». 46 Haroldo Valladão, Direito Internacional Privado: introdução e parte geral. Rio de Janeiro: Livraria Freitas Bastos, 1968, p. 371.

47 Cf. Haroldo Valladão, «O Contrato Internacional», Revista Forense, v. 269, jan./mar. 1980, p. 3. 48 V. Haroldo Valladão, «O Contrato Internacional», Revista Forense, v. 269, jan./mar. 1980, p. 3. 49 Voir Haroldo Valladão, «O Contrato Internacional», Revista Forense, v. 269, jan./mar. 1980, p. 4: «Igualmente a não-referência do art. 9, caput, da Lei de Introdução, à autonomia da vontade, à eleição de lei, à lei do contrato, secular no Brasil (v. H. VALLADÃO, 'Estudos de DIPr', 1947.

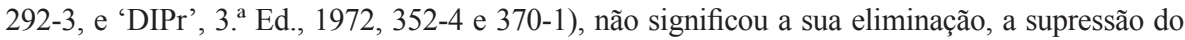
domicílio especial para escolha da lei competente em determinado negócio. Segundo decidiu o Supremo Tribunal Federal, em acórdão do saudoso Min. PHILADELPHO DE AZEVEDO, princípios básicos de nosso direito não podem desaparecer por sua simples omissão num Código ou numa Lei (Ac. em Diário da Justiça, apenso 135, em 12.VI.1945, ps. 2.550-1)». 
justifier selon un souci constitutionnel raisonnable. Il n'y a aucun souci, toutefois, qui justifie l'interdiction aux parties de choisir la loi applicable pour régir les relations de droit privé ${ }^{50}$.

Le Professeur Jacob Dolinger, qui a donné un cours à L'Académie de la Haye ${ }^{51}$ et a publié un livre à ce sujet, admet expressément l'autonomie dans le droit brésilien. ${ }^{52}$

Un autre argument en faveur de l'autonomie de la volonté découle d'une interprétation systématique de l'ordre juridique brésilien. La loi de l'arbitrage ${ }^{53}$ permet aux parties, lorsqu'elles choisissent l'arbitrage pour régler leurs différends, de choisir la loi qui sera appliquée au litige ${ }^{54}$.

$\mathrm{Si}$ on permet l'application du critère de l'autonomie de la volonté devant l'arbitre, pourquoi ne pas la permettre devant le juge étatique ? Est-ce que le mode de résolution des controverses doit interférer dans la loi applicable au contrat ? Est-ce que cela n'heurterait pas le principe de l'indépendance entre la compétence juridictionnelle et la compétence législative?

On aperçoit, donc, que la question est très controversée. C'est probablement la question la plus discutée du droit international privé brésilien au niveau doctrinaire. À mon avis, le critère de l'autonomie de la volonté doit être admis ${ }^{55}$. La jurisprudence des tribunaux supérieurs, toutefois, ne s'est pas encore manifestée.

Comme le règlement de l'arbitrage expressément prévoit la possibilité pour les parties de choisir la loi appliquée au contrat, cela est une des raisons qui stimule les entreprises étrangères qui exercent des activités au Brésil à choisir l'arbitrage comme moyen de résolution des controverses et à éviter le recours à la juridiction étatique. En choisissant

50 Sur le thème, Lauro da Gama e Souza Jr., «Autonomia da vontade nos contratos internacionais do Direito Internacional Privado brasileiro: uma leitura constitucional do art. 9 da LICC em favor da liberdade de escolha do direito aplicável». In Carmen Tiburcio et Luís Roberto Barroso (org.), O Direito Internacional Contemporâneo: Estudos em homenagem ao Professor Jacob Dolinger. Rio de Janeiro: Renovar, 2006, p. 599-626.

51 Jacob Dolinger, «Evolution of principles for resolving conflicts in the field of contracts and torts». Recueil des cours, Volume 283, 2000.

52 Jacob Dolinger, Direito Internacional Privado (Parte Especial): Contratos e obrigações no Direito Internacional Privado, Rio de Janeiro: Renovar, 2007, pp. 421-481.

53 Loi 9.307/96.

54 Loi n 9.307, 1996, art. 2: «A arbitragem poderá ser de direito ou de eqüidade, a critério das partes. § 1 Poderão as partes escolher, livremente, as regras de direito que serão aplicadas na arbitragem, desde que não haja violação aos bons costumes e à ordem pública. § 2 Poderão, também, as partes convencionar que a arbitragem se realize com base nos princípios gerais de direito, nos usos e costumes e nas regras internacionais de comércio».

55 Cf. pour la discussion dans la doctrine brèsilienne, Carmen Tiburcio, «A lei aplicável às arbitragens internacionais». In: Pedro A. Batista Martins et José Maria Rossani Garcez (coord.), Reflexões sobre a arbitragem. São Paulo: Ltr, 2002. 
l'arbitrage, elles peuvent tranquillement choisir l'application, au contrat, d'une loi différente de la lex celebrationis.

En ce qui concerne les contrats de travail, l'énoncé numéro 207 du Tribunal Supérieur du Travail - déjà abrogé - déterminait l'application de la loi du pays où les services ont été exercés ${ }^{56}$. Elle écartait, donc, pour les relations de travail, la règle de l'article 9 de la Loi d'Introduction aux Normes du Droit Brésilien, qui établit le critère de l'application de la lex celebrationis. Maintenant, la jurisprudence utilise le critère de la règle la plus favorable pour le travailleur ${ }^{57}$.

\section{LES PERSONNES MORALES ET LE CONFLIT DE JURIDICTION}

Dans ce domaine, il convient de voir les cas où une entreprise pourra être soumise à la juridiction brésilienne. Les règles de compétence internationale sont fixées aux articles 21, 22 et 23 du Nouveau Code de

56 Tribunal Superior do Trabalho, Enunciado n 207: «A relação jurídica trabalhista é regida pelas leis vigentes no país da prestação de serviço e não por aquelas do local da contratação". 57 La jurisprudence a décidé en faveur de l'application de la loi la plus favorable au travailleur en se basant sur l'article 3, II de la Loi 7.064/1982, laquelle determine que, dans le cas de travailleurs contractés ou transférés pour prêter des services à l'étranger: «A empresa responsável pelo contrato de trabalho do empregado transferido assegurar-lhe-á, independentemente da observância da legislação do local da execução dos serviços: (...) a aplicação da legislação brasileira de proteção ao trabalho, naquilo que não for incompatível com o disposto nesta Lei, quando mais favorável do que a legislação territorial, no conjunto de normas e em relação a cada matéria». Cf. TST, DEJT 21 set. 2012, AIRR 103840-50.2007.5.03.0138, Rel Min. Walmir Oliveira da Costa: «Não obstante o cancelamento da Súmula no 207 do TST pela Resolução $n^{\circ} 181 / 2012$, este Tribunal Superior já vinha adotando iterativo e notório posicionamento no sentido de que o princípio da territorialidade admite exceção, na hipótese de empregado contratado no Brasil e posteriormente transferido para prestar serviços no exterior; caso no qual se aplica, ao invés daquele postulado, o princípio da norma mais favorável, nos termos do artigo $3^{\circ}$, II, da Lei $n^{\circ} 7.064$, de 06/12/82, o qual não se restringe a engenheiros ou a empregados de empresas de engenharia, em face da Lei $n^{\circ} 11.962$, de 03/07/2009, que alterou o art. $1^{\circ}$ da Lei $n^{\circ}$ $7.064 / 82$, justamente para abranger a situação de todos os trabalhadores contratados no Brasil ou transferidos por seus empregadores para prestar serviços no exterior». Dans le même sens: TST, DEJT 27 abr.2012, AIRR 641-86.2010.5.03.0047, Rapporteur. Juge convoqué: Flavio Portinho Sirangel; et TST, DEJT 22 jun.2012, AIRR 295-74.2010.5.03.0035, Rel ${ }^{\mathrm{a}}$. Min ${ }^{\mathrm{a}}$.Maria de Assis Calsing.

Il faut observer que la jurisprudence aplique la règle mentionée même pour des cas pendants avant la publication de la Loi $n^{\circ} 11.962 / / 2009$, laquelle a altéré $1^{\prime}$ article $1^{\circ}$ de la Loi $n^{\circ} 7.064 / 82$, pour étendre l'application de la dite loi pour tous les travailleurs tranférés à l'étranger et pas seulement pour ceux qui sont du secteur de l'ingénieurie: TST, DEJT 19 set.2014, RR 10344091.2007.5.01.0461, Rel Min. Renato de Lacerda Paiva. 
Procédure Civile de 2015. Les articles $21^{58}$ et $22^{59}$ établissent les cas de compétence internationale concurrente et l'article $23^{60}$, les cas de compétence internationale exclusive.

Si l'hypothèse est prévue à l'article 23, seul l'autorité brésilienne pourra la connaître et dans aucune hypothèse une sentence étrangère ne sera homologuée au Brésil; si l'hypothèse est prévue aux articles 21 ou 22, de l'autre coté, en principe, une sentence étrangère pourra être exécutée au Brésil.

L'article 23 détermine que l'autorité judiciaire brésilienne sera compétente, à l'exclusion de toute autre, pour connaître des actions relatives aux immeubles situés au Brésil (la même règle que celle de l'article 44 du Nouveau Code de Procédure Civile Français) et pour les successions des biens situées au Brésil bien que pour la confirmation du testamant particulier, même si la personne décedée est étrangère et a résidée hors du Brésil. De plus, l'article prévoit aussi la compétence exclusive du Pouvoir Judiciaire brésilien dans les cas de divorce ou séparation lorsqu'il y a des biens du couple situés au Brésil

Voyons, maintenant, les cas de compétence internationale concurrente (article 21 et 22 du CPC). Dans ces cas, l'action pourra aussi être soumise à un juge étranger et la sentence étrangère pourra être homologuée au Brésil, même si la même action est en cours au Brésil (art. 24, seul paragraphe, CPC) ${ }^{61}$.

58 Code de Procédure Civile, Loi n 13.105, 2015, art. 21: «Compete à autoridade judiciária brasileira processar e julgar as ações em que: I - o réu, qualquer que seja a sua nacionalidade, estiver domiciliado no Brasil; II - no Brasil tiver de ser cumprida a obrigação; III - o fundamento seja fato ocorrido ou ato praticado no Brasil. Parágrafo único. Para o fim do disposto no inciso I, considera-se domiciliada no Brasil a pessoa jurídica estrangeira que nele tiver agência, filial ou sucursal».

59 Code de Procédure Civile, Loi n 13.105, 2015, art. 22: «Compete, ainda, à autoridade judiciária brasileira processar e julgar as ações: I - de alimentos, quando: a) o credor tiver domicílio ou residência no Brasil; b) o réu mantiver vínculos no Brasil, tais como posse ou propriedade de bens, recebimento de renda ou obtenção de benefícios econômicos; II decorrentes de relações de consumo, quando o consumidor tiver domicílio ou residência no Brasil; III - em que as partes, expressa ou tacitamente, se submeterem à jurisdição nacional». 60 Code de Procédure Civile, Loi n 13.105, 2015, art. 23: «Compete à autoridade judiciária brasileira, com exclusão de qualquer outra: I - conhecer de ações relativas a imóveis situados no Brasil; II - em matéria de sucessão hereditária, proceder à confirmação de testamento particular e ao inventário e à partilha de bens situados no Brasil, ainda que o autor da herança seja de nacionalidade estrangeira ou tenha domicílio fora do território nacional; III - em divórcio, separação judicial ou dissolução de união estável, proceder à partilha de bens situados no Brasil, ainda que o titular seja de nacionalidade estrangeira ou tenha domicílio fora do território nacional».

61 Code de Procédure Civile, Loi n 13.105, 2015, art. 24, seul paragraphe: «A pendência de causa perante a jurisdição brasileira não impede a homologação de sentença judicial estrangeira quando exigida para produzir efeitos no Brasil». 
Ainsi, l'autorité brésilienne sera compétente, de manière non exclusive, si le défendeur est domicilié au Brésil. C'est la règle ordinaire de compétence internationale, la même que celle adoptée dans droit français, résultant de l'application de l'article 42 du Nouveau Code de Procédure Civile (règle de compétence interne qui doit être étendue au niveau international en raison de ce que dispose l'arrêt Scheffel, du 30 octobre 1962, selon lequel «la compétence internationale se détermine par l'extension des règles de compétence territoriale interne ${ }^{62}$.

Le paragraphe unique de l'article 21 consacre une règle similaire à la jurisprudence française des 《gares principales ${ }^{63}$. Dit le paragraphe que seront considérées domiciliées au Brésil les personnes morales étrangères qui y ont une agence, une filiale ou une succursale ${ }^{64}$. Les entreprises étrangères, donc, pourront être assignées devant les cours brésiliennes si elles ont un établissement secondaire au Brésil, pour des litiges liés à cet établissement.

L'article 21, alinéa II prévoit que l'autorité brésilienne aura compétence si l'action se rapporte à une obligation qui doit être accomplie au Brésil. C'est la même hypothèse que celle de l'article 46 du Nouveau Code de Procédure Civile français, selon lequel le demandeur pourra saisir, «en matière contractuelle, la juridiction du lieu de la livraison effective de la chose ou du lieu de l'exécution de la prestation de service», et, «en matière délictuelle, la juridiction du lieu du fait dommageable ou celle dans le ressort de laquelle le dommage a été subi».

Enfin, l'article 21, alinéa III détermine la compétence de l'autorité brésilienne si l'action s'origine d'un fait ou d'un acte qui ont eu lieu au Brésil. Le nouveau Code a aussi inclut la compétence concurrente du judiciaire brésilien dans le cas de pension alimentaire lorsque le créancier a son domicile ou sa résidence au Brésil ou lorsque le défendeur a des biens quelconques au Brésil (art. 22, I du CPC 2015). En plus, le judiciaire brésilien sera aussi compétent dans les cas de consommation quand le consommateur a son domicile ou sa résidence situé au Brésil (art. 22, II du CPC 2015).

Même si une action identique avait été antérieurement introduite en France, cela n'empêcherait pas l'exercice de la juridiction brésilienne,

62 Cass., Civ., 30 oct 1962, Scheffel: «Mais attendu que l'extranéité des parties n'est pas une cause d'incompétence des juridictions françaises, dont, d'autre part, la compétence internationale se détermine par extension des règles de compétence territoriale interne».

63 Yvon Loussouarn et Jean-Denis Bredin, Droit du Commerce International. Paris: Sirey, 1969, p.333: «En matière de conflits de jurisdictions, par extension sur le plan international de la jurisprudence des gares principales, la société étrangère, qui a une succursale en France, peut être assignée au siège de cette dernière, lorsqu'il s'agit d'une opération traitée dans le ressort de la succursale».

64 Jacob Dolinger et Carmen Tiburcio, Direito Internacional Privado: parte geral e processo internacional. Rio de Janeiro: Forense, 2016, p. 563. 
car le droit brésilien, au contraire du droit français, ne reconnaît pas les

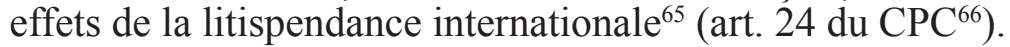

En plus, est-ce que les parties peuvent choisir les tribunaux d'un autre pays pour régler leurs litiges? Après plusieurs décisions en jurisprudence qui ont considèrés que les clauses attributives de juridiction ne pouvaient pas écarter la compétence internationale concurrente de l'autorité brésilienne ${ }^{67}$, le nouveau Code a expréssement admis les effets positifs et négatifs de ce type de clause ${ }^{68}$.

Les effets négatifs des clauses d'élection de for étranger durant de nombreuses années ont été une des questions les plus controversées en ce qui concerne le conflit de juridiction en droit international privé brésilien ${ }^{69}$.

La Cour Suprême avait rendu des arrêts favorables aux clauses d'élection de for étranger pendant les années $50^{70}$, mais la plupart des décisions postérieures, surtout des tribunaux inférieurs, refusent leurs effets négatifs, tout en empêchant qu'une clause qui attribue juridiction à un tribunal étranger puisse écarter la compétence internationale

65 Pontes de Miranda, Comentários ao Código de Processo Civil, Tomo II, Forense 1974, p. 228: «Ineficácia da litispendência de ações propostas no estrangeiro - se alguma ação, que, conforme os artigos 88 e 89 , tenha de ser intentada no Brasil, e o foi perante autoridade judiciária estrangeira (juiz ou tribunal), a litispendência, que existe no estrangeiro, é sem qualquer eficácia para o Brasil. Mesmo se está no fim o curso do processo, ou se já houve sentença, ou se já transitou em julgado, pode ser proposta no Brasil a ação se se trata da mesma causa, isto é, do mesmo mérito, do mesmo direito, pretensão ou ação, ou se apenas há entre as duas causas conexão».

66 Code de Procédure Civile, Loi n 13.105, 2015, art. 24: «A ação proposta perante tribunal estrangeiro não induz litispendência e não obsta a que a autoridade judiciária brasileira conheça da mesma causa e das que lhe são conexas, ressalvadas as disposições em contrário de tratados internacionais e acordos bilaterais em vigor no Brasil».

67 Cf. STJ, DJ 02.out.1989, AR 133/RS, Rel. Min. Cláudio Santos; STJ, DJ 08.ago.2000, REsp 251438/RJ, Rel. Min. Barros Monteiro; et STJ, DJ 19.ago.2008, REsp 804306/SP, Rel. Min. Nancy Adrighi.

68 Effets positifs: «Art. 22. Compete, ainda, à autoridade judiciária brasileira processar e julgar as ações: (...)III - em que as partes, expressa ou tacitamente, se submeterem à jurisdição nacional. »; Effets négatifs: «Art. 25. Não compete à autoridade judiciária brasileira o processamento e o julgamento da ação quando houver cláusula de eleição de foro exclusivo estrangeiro em contrato internacional, arguida pelo réu na contestação ».

69 Avant le Code de Procédure Civil de 2015, sur les effets négatifs de la clause d'élection de for, voir Ricardo Ramalho Almeida, «Breves reflexões sobre eleição de foro estrangeiro e a competência concorrente do Judiciário brasileiro». In João Grandino Rodas, Contratos internacionais, 3.ed. São Paulo: Editora Revista dos Tribunais, 2002, pp. 296-316; Carmen Tiburcio, A eleição de foro estrangeiro e o judiciário brasileiro. Revista de Arbitragem e Mediação, v. 21, 2009, p. 84-113.

70 STF, j. 24.jan.1957, RE n. 30636, Min. Rel. Cândido Motta: «Com efeito, a norma consubstanciada no citado art. 12 não é do interesse do Estado Brasileiro, motivo porque pode ser derrogada por convenção das partes, pela eleição de um foro estranho à jurisdição brasileira, salvante a hipótese de versar a ação controvérsia sobre imóveis situados em território nacional». 
concurrente des juges nationaux ${ }^{71}$.

Dans le Nouveau Code de Procédure Civile, qui vient d'entrer en vigueur, il y a une règle qui changera ce cadre, comme déjà observé.

EnFrance, les effets négatifs des clauses attributives de juridiction sont reconnus dès les années 30. En 1985, la règle de principe fut reproduite à l'arrêt Compagnie de Signaux et d'Entreprises Électriques, selon laquelle: «les clauses prorogeant la compétence internationale sont en principe licites, lorsqu'il s'agit d'un litige international, comme c'était en l'espèce, et lorsque la clause ne fait pas échec à la compétence territoriale d'une juridiction française» ${ }^{72}$.

Jusqu'à l'entrée en vigueur du Code de Procédure Civile de 2015, le traitement des clauses compromissoires établissant l'arbitrage, était beaucoup plus favorable que celui des clauses attributives de juridiction.

La Loi de l'Arbitrage de 1996 a inauguré un régime qui a permis l'ample développement de l'arbitrage au Brésil, surtout après l'année 2001, lorsque la Cour Suprême a déclaré la constitutionalité de cette Loi $^{73}$ par rapport au principe constitutionnel selon lequel rien ne peut empêcher l'accès d'une personne au Pouvoir Judiciaire ${ }^{74}{ }^{75}$. La Loi garantit le caractère obligatoire des clauses compromissoires, dont l'exécution peut être menée par le Pouvoir Judiciaire, qui a le pouvoir de déterminer l'installation de l'arbitrage, même si l'un des plaideurs ne le veut pas. Peu importe, pour cela, que l'arbitrage ait lieu au Brésil ou à l'étranger.

Ainsi, si un contrat célébré au Brésil prévoit que les litiges seront réglés par un arbitrage établi en France, le juge brésilien ne pourra pas les juger. Si une des parties se refuse à se soumettre à l'arbitrage, l'autre partie pourra recourir au juge étatique pour l'y obliger. Le Pouvoir Judiciaire brésilien en général est très favorable au développement de l'arbitrage et très rarement, dans des conditions très exceptionnelles, intervient contrairement à l'arbitrage. Cela a fait du Brésil l'un des pays les plus favorables à l'arbitrage dans le monde.

Il y a une lacune législative au Brésil en ce qui concerne les aspects du droit international privé des faillites. La Loi 11.101 de 2005 (Loi de Faillite) semble avoir établie, dans le même temps, un système

71 Cf. Ricardo Ramalho Almeida, «Breves reflexões sobre eleição de foro estrangeiro e a competência concorrente do Judiciário brasileiro». In João Grandino Rodas, Contratos internacionais, 3.ed. São Paulo: Editora Revista dos Tribunais, 2002, pp. 296-316.

72 Cf. B. Ancel et Y. Lequette, Grands arrêts de la jurisprudence française de droit international privé, Paris: Dalloz, p. 645 et suivantes.

73 STF, DJ 30.abr.2004, Agravo Regimental em Sentença Estrangeira n 5206-7, Rel. Min. Sepúlveda Pertence.

74 Constitution Féderale Brésilienne, art. 5ème, XXXV: «a lei não excluirá da apreciação do Poder Judiciário lesão ou ameaça a direito».

75 Sur la question, v. Jacob Dolinger et Carmen Tiburcio, Direito Internacional Privado: Arbitragem Comercial Internacional. Rio de Janeiro: Renovar, 2003, p. 49-69. 
universel au niveau interne et territorial au niveau international.

Ainsi, son article 3 détermine que sera compétent pour déclarer la faillite et pour approuver le plan de récupération de l'entreprise en crise financière le for de son principal établissement ${ }^{76}$. C'est une règle de compétence interne et, au niveau interne, elle signifie que toute question patrimoniale concernant l'entreprise en crise devra être soumise au juge de la faillite.

$\mathrm{Si}$ on admet que cette règle puisse être étendue au niveau international, toutefois, il y aura quelques difficultés. Premièrement, on constatera que le critère adopté par la Loi de Faillite (le principal établissement) est différent de celui adopté pour déterminer la nationalité brésilienne des personnes morales (l'incorporation). ${ }^{77}$ Deuxièmement, ce qui est le grand problème, c'est la question de l'extension de la déclaration de faillite: si elle est limitée au territoire national ou si elle peut s'étendre aux établissements qui cette entreprise a à l'étranger ${ }^{78}$.

En même temps, une autre question très polémique est celle de savoir les effets qu'une déclaration de faillite à l'étranger peut produire en relation aux établissements secondaires que l'entreprise a au Brésil.

Toutes ces questions sont très discutées. Il semble que la loi a consacrée, pour le plan international - au contraire de ce que le même article 3 établit pour le niveau interne -, un régime purement territorialiste, ce qui signifie que les effets de la déclaration de faillite sont limités au territoire du pays du juge qui l'a déclarée.

Ainsi, la compétence internationale du juge brésilien serait limitée aux établissements situés au Brésil, peu importe s'il s'agit du principal établissement ou d'un établissement secondaire. La jurisprudence admet, toutefois, l'homologation de sentences étrangères qui déclarent la faillite d'une entreprise étrangère pour que cette déclaration puisse produire des effets en relation à l'agence, à la filiale ou à la succursale

76 Sur le thème, v. Fábio Ulhôa Coelho, Comentários à nova Lei de Falências e Recuperação de Empresas, 6.ed. São Paulo: Saraiva, 2009, p. 26, 27 et 28. Cf. aussi Manoel Justinho Bezerra Filho, Lei de Recuperação de Empresas e Falências Comentada, 4.ed. São Paulo: Editora Revista dos Tribunais, 2007, p. 55, 56 et 57.

77 V. Fábio Ulhôa Coelho, Comentários à nova Lei de Falências e Recuperação de Empresas, 6.ed. São Paulo: Saraiva, 2009, p. 27.

78 Il est intéressant de remarquer que le Tribunal de Rio de Janeiro (TJRJ) a rendu une décision dans le cas OGX admetant l'inclusion des entreprises indépendantes constituées à l'étranger et controlées par l'entreprise mère dans la récuperation judiciale de l'entreprise au Brésil (TJRJ, DJ 16.04.2014, Embargos de Declaração no AI 0064658-77.2013.8.19.0000, Rel. Des Gilberto Campista Guarino). Á l'inverse, il faut noter la décision rendue à propos de la récuperation judiciaire de l'entreprise Sete Brasil, dans laquelle le juge a décidé qu'il n'était pas possible d'inclure les entreprises situées à l'étranger, indépendantes de la maison mère. ( $3^{\mathrm{a}}$ Vara Empresarial do Rio de Janeiro, Proc. no 0142307-13.2016.8.19.0001,Juge: Luiz Alberto Carvalho Alves). 
située au Brésil ${ }^{79}$. Il faut, donc, une altération législative qui puisse clarifier le régime de la faillite internationale au Brésil.

Finalement, il convient de dire quelques mots au sujet des rélations internationales de consommation. Un arrêt très important a été rendu en 2000. Un individu avait acheté, aux États-Unis, une caméra de la marque Panasonic. En arrivant au Brésil, l'appareil a montré de problèmes. L'individu a donc cherché l'assistance technique de la Panasonic au Brésil, qui lui a refusé de faire jouer la garantie sous le fondement que l'entreprise brésilienne (Panasonic du Brésil) était différente de celle qui avait vendu l'appareil (Panasonic International), et que le produit n'était même pas offert sur le marché brésilien.

La Cour Supérieure de Justice, toutefois, a considéré que le consommateur pouvait se prévaloir du lien économique entre les deux marques et que le représentant de Panasonic au Brésil devrait être responsable pour les vices du produit commercialisé par la marque Panasonic International, à laquelle le consommateur avait déposé sa confiance lorsqu'il a acheté le produit. Cet arrêt Panasonic permet aux consommateurs qui achètent des produits à l'étranger de proposer au Brésil des actions en justice contre l'entreprise représentant la marque étrangère, même si le produit n'a pas été mis dans le marché brésilien ${ }^{80}$.

\section{CONSIDÉRATIONS FINALES}

Je viens de vous présenter un bref panorama du droit international privé brésilien concernant les personnes morales et leurs activités. En ce qui concerne la nationalité étrangère des entreprises, le Brésil adopte le critère de l'incorporation. Toutefois, pour qu'une entreprise soit brésilienne, elle doit être incorporée au Brésil et avoir son siège administratif au pays. Il y a quelques activités total ou partiellement interdits pour les personnes morales étrangères: par exemple, la

79 Cf. STJ, DJ 24.mar.1997, REsp 15708/RS, Rel. Min. Costa Leite: «Contrato de exportação. Ação de cobrança. Exceção de incompetência. Hipótese em que, respeitada a base fática do acórdão, no que diz com a definição do lugar do cumprimento de obrigação, cumpria reconhecer a competência da Justiça brasileira. Sentença estrangeira declaratória de falência só tem eficácia no Brasil depois de homologada pelo STF. Recurso não conhecido». Dans le même sens, v. STJ, DJ 22.ago.1994, REsp 19263/RS, Rel. Min. Antônio Torreão Braz. Toutefois, il y a une observation à faire sur le thème: la Constitution Brésilienne de 1988 a été modifiée par l'Amendement Constitutionnel n. 45 de 2004. La Cour Supérieure de Justice (STJ), selon l'article 105, I, alinéa «i», est le Tribunal compétent pour homologuer les sentences étrangères. Auparavant, le Tribunal compétent pour homologuer les sentences étrangères était la Cour Constitutionelle brésilienne (STF). Ce sujet est controversé au Brésil: il y a des décisions par lesquelles le STJ a réfusé la reconnaissance (STJ, DJ 16 fev.2011, SEC 1734/PT, Rel Min. Felix Fischer et STJ, DJ 03 jun.2011, SEC 1735/PT, Rel. Min, Arnaldo Esteves Lima.

80 STJ, DJ 20.nov.2000, REsp 63981/SP, Rel. Min. Aldir Passarinho Júnior, Rel. p/ acórdão Min. Sálvio de Figueiredo Teixeira. 
Constitution interdit les personnes étrangères d'être propriétaires de moyens de communication et d'obtenir des concessions pour explorer des ressources minérales et hydriques et il y a quelques restrictions aux personnes morales étrangères pour l' acquisition des immeubles ruraux.

Les personnes morales étrangères obéissent à la loi de leur nationalité en ce qui concerne leur capacité et à la loi brésilienne en concernant leur activités au pays. En plus, la règle générale à propos des contrats est l' application de la loi du lieu où le contrat a été conclu, sauf pour des contrats de travail, quand on applique la loi où les services ont été exercés. La possibilité de choisir la loi applicable aux contrats est beaucoup controversée soit dans la doctrine soit dans la jurisprudence.

Finalement, en ce qui concerne la juridiction, l'autorité brésilienne sera compétente, de manière non exclusive, si le défendeur est domicilié au Brésil. La législation détermine que seront considérées domiciliées au Brésil les personnes morales étrangères qui y ont une agence, une filiale ou une succursale. Cela veut dire que les entreprises étrangères pourront être assignées devant les cours brésiliennes si elles ont un établissement secondaire au Brésil, pour des litiges liés à cet établissement. En plus, le juge brésilien sera compétent si l'action se rapporte à une obligation qui doit être accomplie au Brésil ou si l'action s'origine d'un fait ou d'un acte qui ont eu lieu au Brésil. En matière de consommation, le juge brésilien est compétent quand le consommateur a son domicile ou sa résidence au Brésil. De plus, en ce qui concerne les immeubles situés au Brésil, le Pouvoir Judiciaire brésilien est exclusivement compétent. Bien que les clauses attributives de juridiction ont toujours été controversées chez nous, heureusement, dorénavant le Code de Procédure Civil de 2015 les a expressément admises.

\section{REFERENCES}

ANGLATERRE: Restatement Second, Conflict of Laws, 297; A. V. Dicey et J. H. C. Morris, The Conflict of Laws, 8. ed. Londres: Stevens \& Sons Limited, 1967, règle $\mathrm{n} 70$.

ALMEIDA, Ricardo Ramalho. Breves reflexões sobre eleição de foro estrangeiro e a competência concorrente do Judiciário brasileiro. In GRANDINO RODAS, João. Contratos internacionais, 3.ed. São Paulo: Editora Revista dos Tribunais, 2002.

ARAÚJO, Nadia de. Contratos Internacionais e a Jurisprudência Brasileira: Lei Aplicável, Ordem Pública e Cláusula de eleição de foro. In GRANDINO RODAS, João. Contratos internacionais, 3.ed. São Paulo: Editora Revista dos Tribunais, 2002.

BARCELONA TRACTION, Light and Power Company, Limited 
,arrêt, C.I.J. Recueil 1970.

BATTIFOL, Henri et LAGARDE, Paul. Droit International Privé, t. 1, 6.ed. Paris: Librairie générale et de jurisprudence, 1974.

BEZERRA FILHO, Manoel Justinho. Lei de Recuperação de Empresas e Falências Comentada, 4.ed. São Paulo: Editora Revista dos Tribunais, 2007.

Code de Procédure Civile, Loi n 13.105, 2015.

COELHO, Fábio Ulhôa. Comentários à nova Lei de Falências e Recuperação de Empresas, 6.ed. São Paulo: Saraiva, 2009.

DERRUPPE Jean. Droit International Privé, 5.ed. Paris: Dalloz, 1978.

DOLINGER, Jacob et TIBURCIO, Carmen, Direito Internacional Privado: parte geral e processo internacional. Rio de Janeiro: Forense, 2016.

DOLINGER, Jacob. Direito Internacional Privado (Parte Especial): Direito Civil Internacional, v. II. Rio de Janeiro: Renovar, 2002.

DOLINGER, Jacob. Evolution of principles for resolving conflicts in the field of contracts and torts. Recueil des cours, Volume 283, 2000.

LOUSSOUARN, Yvon et BREDIN, Jean-Denis. Droit du Commerce International. Paris: Sirey, 1969.

LOWENFELD, Andreas F. Recueil des cours, Volume 163 (1979-II).

MARTINS, Pedro A. Batista et GARCEZ, José Maria Rossani (coord.). Reflexões sobre a arbitragem. São Paulo: Ltr.

MIRANDA, Pontes de. Comentários ao Código de Processo Civil, Tomo II, Forense 1974.

SCHAPIRA, Jean. Le Droit International des Affaires. Paris: Presses Universitaires de France, 1972.

SERPA LOPES, Miguel Maria de. Comentário Teórico e Prático da Lei de Introdução ao Código Civil, v. III. Rio de Janeiro : Livraria Jacintho, 1946.

STJ, DJ 02.out.1989, AR 133/RS, Rel. Min. Cláudio Santos; STJ, DJ 08.ago.2000, REsp 251438/RJ, Rel. Min. Barros Monteiro; et STJ, DJ 19.ago.2008, REsp 804306/SP, Rel. Min. Nancy Adrighi.

STJ, DJ 24.mar. 1997, REsp 15708/RS, Rel. Min. Costa Leite: «Contrato de exportação. Ação de cobrança. Exceção de incompetência.

STJ, DJ 20.nov.2000, REsp 63981/SP, Rel. Min. Aldir Passarinho Júnior, Rel. p/ acórdão Min. Sálvio de Figueiredo Teixeira. 
STF, j. 24.jan.1957, RE n. 30636, Min. Rel. Cândido Motta: «Com efeito, a norma consubstanciada no citado art. 12 não é do interesse do Estado Brasileiro, motivo porque pode ser derrogada por convenção das partes, pela eleição de um foro estranho à jurisdição brasileira, salvante a hipótese de versar a ação controvérsia sobre imóveis situados em território nacional».

TIBURCIO. Carmen. A eleição de foro estrangeiro e o judiciário brasileiro. Revista de Arbitragem e Mediação, v. 21, 2009.

TJRJ, DJ 16.04.2014, Embargos de Declaração no AI 006465877.2013.8.19.0000, Rel. Des Gilberto Campista Guarino.

VALLADÃO, Haroldo. Direito Internacional Privado: introdução e parte geral. Rio de Janeiro: Livraria Freitas Bastos, 1968.

VALLADÃO, Haroldo.O Contrato Internacional. Revista Forense, v. 269, jan./mar. 1980.

Y SIRVEN, Antonio S. de Bustamante. Derecho Internacional Privado, V. I. 